\title{
Profil endoskopi gastrointestinal di RSUP Prof. Dr. R. D. Kandou Manado periode Januari 2016 - Agustus 2016
}

\author{
${ }^{1}$ Giovanni A. Kaminang \\ ${ }^{2}$ Bradley J. Waleleng \\ ${ }^{2}$ Efata B. I. Polii
}

\author{
${ }^{1}$ Kandidat Skripsi Fakultas Kedokteran Universitas Sam Ratulangi Manado \\ ${ }^{2}$ Bagian/SMF Ilmu Penyakit Dalam Fakultas Kedokteran \\ Universitas Sam Ratulangi Manado \\ Email: giokaminang@yahoo.com
}

\begin{abstract}
Gastrointestinal Endoscopy (GIE) is a technique in gastroenterology - hepatology to directly see condition of the gastrointestinal tract by using a tool called endoscope. For endoscopy in the upper gastrointestinal tract is called esophagogastroduodenoscopy (EGD). Besides Esophagogastroduodenoscopy there is also colonoscopy, is used to evaluate the condition of lower gastrointestinal tract, in the area of rectum, sigmoid colon, descending colon, transverse colon, ascending colon, cecum, and also ileum.This research is aimed to understanding profile of gastrointestinal endoscopy in patients in RSUP Prof. Dr. R. D. Kandou Manado period January 2016 - August 2016. This was a descriptive retrospective study using taking secondary data of patients from Medical Record Department of Prof. Dr. R. D. Kandou Hospital Manado. The results showed that there 59 patients with endoscopy examination performed on them. The majority of patients were 30 males (51\%), age group 50-59 years old (30\%), with dyspepsia (epigastric pain) as indication (57\%), EGD (80\%), and chronic gastritis plus Helicobacter pylori infection as diagnosis after biopsy (38\%).
\end{abstract}

Keywords: endoscopy, indication, diagnosis

\begin{abstract}
Abstrak: Endoskopi gastrointestinal (EGI) merupakan salah satu teknik dalam ilmu gastroenterology-hepatologi untuk melihat secara langsung keadaan di dalam saluran cerna dengan menggunakan alat yang bernama endoskop. Pemeriksaan endoskopi pada saluran cerna bagian atas disebut esofagogastrodudenoskopi (EGD) sedangkan kolonoskopi digunakan untuk mengevaluasi serta memeriksa lumen pada saluran cerna bagian bawah, yaitu pada daerah rektum, kolon sigmoid, kolon desenden, kolon transversum, kolon asenden, sekum, serta ileum. Penelitian ini bertujuan unutk mengetahui profil EGI pada pasien di RSUP Prof. DR. R. D. Kandou periode Januari 2016-Agustus 2016. Jenis penelitian ialah deskriptif retrospektif dengan menggunakan data sekunder pasien di Instalasi Rekam Medik RSUP Prof. Dr. R. D. Kando Manado. Dari hasil penelitian diperoleh pasien yang melakukan pemeriksaan endoskopi sebanyak 59 orang. Mayoritas pasien ialah pasien jenis kelamin laki-laki sebanyak 30 orang (51\%), kelompok usia 50-59 tahun (30\%), dengan indikasi dispepsia (nyeri epigastrium) (57\%), tindakan endoskopi jenis EGD (80\%), dan diagnosis dibiopsi gastritis kronik dengan infeksi Helicobacter pylori (38\%).
\end{abstract}

Kata kunci: endoskopi, indikasi, diagnosis

Endoskopi gastrointestinal (EGI) merupakan salah satu teknik dalam ilmu gastroenterologi-hepatologi untuk melihat secara langsung keadaan di dalam saluran cerna dengan menggunakan alat yang bernama endoskop. Endoskop adalah alat untuk melakukan pemeriksaan penunjang untuk diagnosis bahkan alat endoskop juga 
dipakai untuk tindakan terapeutik di saluran pencernaan. Seiring dengan berjalannya waktu endoskopi berevolusi dari endoskopi yang berjenis kaku dengan kemampuan yang terbatas ke endoskopi yang berjenis lentur dan lebih canggih dengan kemampuan pencitraan yang lebih baik, dan mempunyai ciri khusus untuk melakukan intervensi terapeutik serta memiliki desain yang berbeda untuk memungkinkan melakukan pemeriksaan pada daerah tertentu dari saluran pencernaan. ${ }^{1}$

Dewasa ini, hampir seluruh rumah sakit memiliki endoskopi sebagai suatu sarana pemeriksaan penunjang untuk membantu menegakkan diagnosis suatu penyakit dari gangguan saluran pencernaan. Adanya pemeriksaan endoskopi ini, membantu dan memudahkan pengobatan karena diagnosis dapat ditegakkan secara akurat.

Pemeriksaan endoskopi pada saluran cerna bagian atas disebut Esofagogastroduodenoskopi (EGD) untuk mengevaluasi keadaan mukosa di saluran cerna bagian atas dan sekitarnya. ${ }^{2}$ Selain EGD, terdapat pula pemeriksaan kolonoskopi yang digunakan untuk mengevaluasi serta memeriksa lumen pada saluran cerna bagian bawah, yaitu daerah rektum, kolon sigmoid, kolon desenden, kolon transversum, kolon asenden, sekum, serta ileum. ${ }^{3}$

Selain pemeriksaan secara langsung lumen pada saluran cerna, endoskopi juga mempunyai metode lain untuk melakukan pemeriksaan bahkan untuk melakukan tindakan pengobatan (terapeutik) pada pankreas dan sistem bilier. Endoscopy Retrograde Cholangiopancreatography (ERCP) menyediakan gambaran endoskopi yang baik pada duktus bilier dan duktus pankreatikus. ${ }^{4}$

Sebelum melakukan pemeriksaan endoskopi perlu diperhatikan tindakantindakan pada pre-endoskopi, baik pada pemeriksaan endoskopi saluran cerna bagian atas maupun pada saluran cerna bagian bawah. Perlu juga diberitahukan kepada pasien serta keluarga indikasi dan kontraindikasi dari pelaksanaan pemeriksaan endoskopi, agar pasien serta keluarga dapat mengetahui dengan pasti hal-hal yang akan dilakukan pada saat pemeriksaan. Perlu diperhatikan juga informed consent (dokumen tindakan medis) sebelum melakukan tindakan pemeriksaan endoskopi.

Berdasarkan data di Pusat Endoskopi Saluran Cerna (PESC) di Rumah Sakit Cipto Mangunkusumo, terdapat peningkatan sebanyak $26,2 \%$ untuk pelayanan endoskopi dari tahun 2010 sebanyak 1.825 pasien sampai tahun 2011 sebanyak 2.303 pasien, baik yang menerima pelayanan untuk diagnosis bahkan terapeutik di bagian Gastroenterologi. ${ }^{5}$

Penelitian ini bertujuan untuk mengetahui profil endoskopi gastrointestinal yang melakukan pemeriksaan Endoskopi di RSUP Prof. DR. R. D. Kandou periode Januari 2016 - Agustus 2016.

\section{METODE PENELITIAN}

Jenis penelitian yang dilakukan ialah deskriptif retrospektif dengan menggunakan data sekunder di Instalasi Rekam Medik RSUP Prof. Dr. R. D. Kandou periode Januari 2016-Agustus 2016. Populasi penelitian ialah pasien yang dilakukan pemeriksaan endoskopi gastrointestinal di RSUP Prof. Dr. R. D. Kandou periode Januari 2016-Agustus 2016. Sampel penelitian ialah semua data rekam medis pasien gangguan gastrointestinal yang melakukan pemeriksaan endoskopi gastrointestinal di RSUP Prof. DR. R. D. Kandou periode Januari 2016-Agustus 2016.

Variabel penelitian antara lain usia, jenis kelamin, indikasi melakukan pemeriksaan endoskopi, tindakan endoskopi, hasil patologi anatomi.

\section{HASIL PENELITIAN}

Dari hasil penelitian yang dilakukan di RSUP Prof. Dr. R. D. Kandou Manado periode Januari - Agustus 2016, didapatkan pasien yang melakukan pemeriksaan endoskopi gastrointestinal di poli endoskopi RSUP Prof. Dr. R. D. Kandou 
Manado yang memenuhi kriteria inklusi sebanyak 59 pasien. Dari 59 pasien tersebut didapatkan pasien berjenis kelamin lakilaki sebanyak 30 pasien $(51 \%)$ dan yang berjenis kelamin perempuan sebanyak 29 pasien (49\%) (Gambar 1).

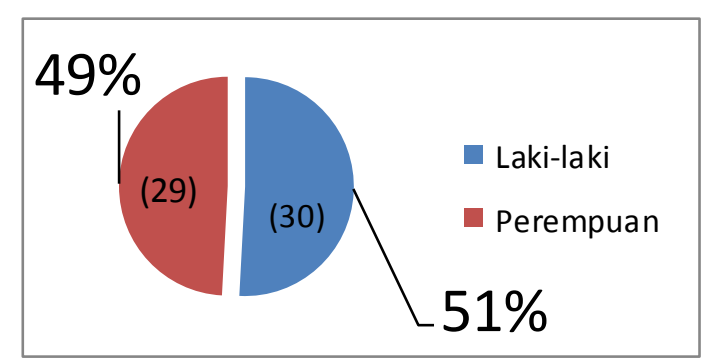

Gambar 1. Distribusi pasien yang melakukan pemeriksaan Endoskopi berdasarkan jenis kelamin

Dari 59 pasien yang melakukan pemeriksaan endoskopi di poli endoskopi RSUP Prof. DR. R. D. Kandou Manado, didapatkan kelompok usia 20-29 tahun sebanyak 1 pasien (2\%); kelompok usia 3039 tahun sebanyak 17 pasien (29\%); kelompok usia 40-49 tahun sebanyak 11 pasien (19\%); kelompok usia 50-59 tahun sebanyak 18 pasien (30\%); kelompok usia 60-69 tahun sebanyak 10 pasien (17\%); dan kelompok usia 70-79 tahun sebanyak 2 pasien (3\%) (Gambar 2).

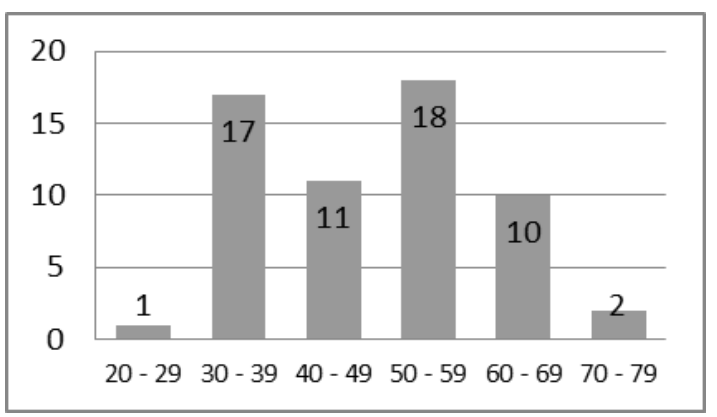

Gambar 2. Distribusi pasien yang melakukan pemeriksaan endoskopi berdasarkan kelompok usia

Berdasarkan Tabel 1, dari 59 pasien yang melakukan pemeriksaan endoskopi di poli endoskopi RSUP Prof. DR. R. D. Kandou Manado didapatkan bahwa sebagian besar pasien yang melakukan pemeriksaan berdasarkan indikasi dispepsia (nyeri epigastrium) yaitu sebanyak 34 pasien $(57 \%)$.

Tabel 1. Distribusi pasien yang melakukan pemeriksaan Endoskopi berdasarkan indikasi

\begin{tabular}{lcc}
\hline \multicolumn{1}{c}{ Indikasi } & Jumlah & (\%) \\
\hline $\begin{array}{l}\text { Radang usus besar } \\
\text { Perdarahan rectum }\end{array}$ & 1 & 2 \\
$\begin{array}{l}\text { Nyeri perut + BAB } \\
\text { berwarna hitam }\end{array}$ & 1 & 2 \\
$\begin{array}{l}\text { Dispepsia (Nyeri } \\
\text { Epigastrium) }\end{array}$ & 34 & 57 \\
BAB berwarna & 7 & 11 \\
hitam & & 15 \\
BAB + darah segar & 9 & 2 \\
$\begin{array}{l}\text { Sering kembung } \\
\text { Nyeri perut }\end{array}$ & 1 & 3 \\
$\begin{array}{l}\text { Hematemesis } \\
\text { melena }\end{array}$ & 2 & 2 \\
$\begin{array}{l}\text { Sulit BAB } \\
\text { Nyeri perut kanan } \\
\text { bawah }\end{array}$ & 1 & 2 \\
\hline
\end{tabular}

Gambar 3 memperlihatkan dari 59 pasien yang melakukan pemeriksaan endoskopi di poli endoskopi RSUP Prof. DR. R. D. Kandou Manado didapatkan pasien yang menerima tindakan endoskopi EGD sebanyak 47 pasien (80\%) dan pasien yang menerima tindakan endoskopi kolonoskopi sebanyak 12 pasien (20\%).

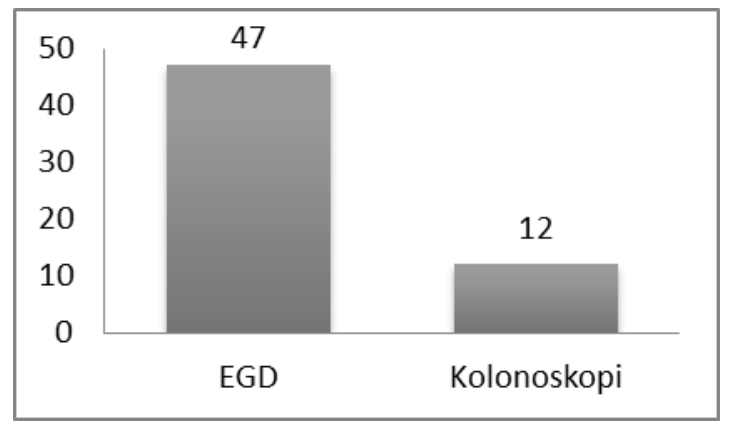

Gambar 3. Distribusi pasien yang melakukan pemeriksaan Endoskopi berdasarkan tindakan Endoskopi

Berdasarkan data yang didapat, dari 59 pasien yang melakukan pemeriksaan endoskopi di poli endoskopi RSUP Prof. Dr. R. D. Kandou Manado didapatkan pasien yang didiagnosis dengan kolitis 
sebanyak 1 pasien (2\%), polip rektum sebanyak 1 pasien $(2 \%)$, gastritis kronik + infeksi Helicobacter pylori sebanyak 23 pasien (38\%), gastritis erosif sebanyak 1 pasien (2\%), gastritis kronik sebanyak 5 pasien (8\%), gastritis kronik erosif + infeksi Helicobacter pylori sebanyak 2 pasien $(3 \%)$, gastritis kronik dengan fibrous ringan + infeksi Helicobacter pylori sebanyak 1 pasien $(2 \%)$, adenokarsinoma rektum diferensiasi baik sebanyak 1 pasien (2\%), radang kronis sebanyak 1 pasien (2\%), radang non spesifik + infeksi Helicobacter pylori di antrum sebanyak 1 pasien (2\%), kolitis kronik sebanyak 1 pasien (2\%), gastritis kronik antrum sebanyak 3 pasien (4\%), gastritis kronik antrum + infeksi Helicobacter pylori sebanyak 2 pasien (3\%), adenokarsinoma diferensiasi sedang sigmoid sebanyak 1 pasien $(2 \%)$, gastritis kronik antrum dan corpus + infeksi Helicobacter pylori sebanyak 2 pasien (3\%), adenokarsinoma diferensiasi buruk sebanyak 1 pasien (2\%), gastritis kronik antrum dan korpus sebanyak 2 pasien (3\%), radang kronis pada antrum dan corpus sebanyak 1 pasien (2\%), gastritis kronik erosif sebanyak 1 pasien (2\%), gastritis kronik erosif dengan fokus fibrosis sebanyak 1 pasien (2\%), ileitis kronik non spesifik sebanyak 2 pasien (3\%), kolitis non spesifik sebanyak 1 pasien $(2 \%)$, papillary adenocarcinoma kolon dessenden diferensiasi sedang + infeksi Helicobacter pylori sebanyak 2 pasien (3\%), polip inflammatory sebanyak 1 pasien (2\%), dan polip adenomatosa kolon transversum sebanyak 1 pasien $(2 \%)$. Sebagai diagnosis terbanyak ialah gastritis kronik disertai infeksi Helicobacter pylori sebanyak 23 pasien (38\%).

\section{BAHASAN}

Dari hasil penelitian deskriptif retrosepktif dengan menggunakan data pasien yang melakukan pemeriksaan EGI di Bagian Poli Endoskopi periode Januari 2016-Agustus 2016 di RSUP Prof. Dr. R. D. Kandou Manado, didapatkan sebanyak 59 pasien yang memenuhi kriteria inklusi. Berdasarkan data yang dikumpulkan, pasien yang berjenis kelamin laki-laki berjumlah lebih banyak dari pada pasien perempuan. Hal yang serupa dengan hasil pemeriksaan endoskopi di Good Samjung Hospital periode Juni-Desember 2012, dengan jumlah data pasien yang melakukan pemeriksaan endoskopi lebih banyak pada pasien laki-laki dibandingkan perempuan. ${ }^{6}$

Berdasarkan data pasien yang melakukan pemeriksaan endoskopi, kelompok usia 50-59 tahun memiliki jumlah yang lebih banyak dibandingkan dengan kelompok usia yang lain. Hal serupa juga didapatkan pada penelitian yang menggunakan data pasien yang melakukan pemeriksaan endoskopi di RSUP Dr. M. Djamil yaitu ditemukan kelompok usia terbanyak yang melakukan pemeriksaan endoskopi ialah 41-50 tahun. ${ }^{7}$ Pada penelitian yang dilakukan oleh Ariefisny et al. ${ }^{8}$ ditemukan bahwa insidensi paling banyak untuk penderita gastritis kronik yang disebabkan oleh Helicobacter pylori ialah 51-60 tahun. Angka kejadian gastritis kronik yang disebabkan oleh Helicobacter pylori maupun tanpa bakteri pada usia tua lebih tinggi dibandingkan dengan usia muda. Hal ini menunjukkan bahwa seiring dengan bertambahnya usia, mukosa gaster cenderung menipis sehingga lebih rentan terhadap infeksi bakteri Helicobacter pylori dan gangguan pada gaster serta berindikasi untuk dilakukan pemeriksaan endoskopi. ${ }^{8}$

Data pasien yang melakukan tindakan endoskopi berdasarkan indikasi memperlihatkan bahwa pasien dengan indikasi dispepsia (nyeri epigastrium) memiliki jumlah yang lebih banyak daripada indikasi lainnya. Hal ini ditemukan juga pada penelitian oleh Teriaky et al. ${ }^{9}$ yang menunjukkan bahwa indikasi terbanyak dari EGD ialah dispepsia. Pada penelitian yang dilakukan oleh Putri et al. ${ }^{7}$ mendapatkan bahwa pasien disepsia dengan keluhan nyeri pada epigastrium memiliki jumlah terbanyak. Nyeri epigastrium merupakan keluhan dispepsia yang paling sering menjadi alasan utama untuk berobat ke ahli gastroenterologi dan penyebab bagi seseorang untuk tidak bekerja. ${ }^{10}$ Hal ini 
terjadi dikarenakan oleh berbagai faktor penyebab dispepsia, yaitu faktor diet dan lingkungan, ambang rangsang persepsi, sekresi asam lambung, serta infeksi Helicobacter pylori. ${ }^{11}$

Berdasarkan data tindakan endoskopi, EGD merupakan tindakan endoskopi yang lebih banyak digunakan untuk melakukan pemeriksaan dibandingkan kolonoskopi. Pada data pasien yang melakukan pemeriksaan endoskopi saluran cerna di RSPAD Gatot Soebroto Ditkesad Jakarta, didapatkan yang melakukan pemeriksaan EGD sebanyak 31 dari 38 pasien. $^{12}$ Dispepsia/nyeri epigastrium merupakan gejala tersering yang dikeluhkan oleh pasien dengan gangguan saluran cerna, sehingga berindikasi untuk dilakukan pemeriksaan endoskopi saluran cerna bagian atas, yaitu EGD.

Hasil penelitian pasien yang melakukan pemeriksaan endoskopi berdasarkan diagnosis mendapatkan bahwa gastritris kronis disertai infeksi Helicobacter pylori merupakan diagnosis yang lebih banyak ditemukan melalui pemeriksaan endoskopi dan hasil biopsi dibandingkan dengan diagnosis lainnya. Hal serupa ditemukan pada prevalensi gastritis kronik di Indonesia yaitu lebih dari $80 \%$ disebabkan oleh infeksi bakteri Helicobacter pylori. ${ }^{13}$ Hal ini terjadi antara lain karena asupan alkohol berlebihan, merokok, penggunaan obat-obatan NSAID, makanan yang dapat merangsang asam lambung, dan stress. ${ }^{8,14,15}$

\section{SIMPULAN}

Dari hasil penelitian dan bahasan dapat disimpulkan bahwa mayoritas pasien ialah laki-laki, kelompok usia 50-59 tahun, dengan indikasi dispepsia/nyeri epigastrium, tindakan endoskopi EGD, dan diagnosis setelah biopsi gastritis kronik disertai infeksi Helicobacter pylori.

\section{SARAN}

Disarankan bagi pihak tenaga medis dan pihak RSUP Prof. Dr. R. D. Kandou Manado agar lebih memperhatikan kelengkapan status dan sebaiknya dilakukan perbaikan dalam pencatatan data sekunder agar data yang diperoleh lebih lengkap yang akan sangat membantu kelancaran penelitian.

Bagi peneliti selanjutnya agar dapat melakukan penelitian lebih lanjut mengenai pemeriksaan endoskopi bahkan tindakan terapeutik endoskopi mengingat kurangnya sumber data dan informasi. Diharapkan penelitian ini dapat menjadi bahan acuan, sumber data sehingga penelitian selanjutnya dapat melengkapi kekurangan dalam penelitian ini.

\section{DAFTAR PUSTAKA}

1. American Society for Gastrointestinal Endoscopy. GI endoscopes. 2011 [cited 2016 Aug 20]. Available from: http://www.asge.org/uploadedFiles/Pub lications_and_Products/Technology_R eviews/GI\%20Endoscopes(1).pdf

2. Kyoung OK. Normal upper GI findings and normal variants. In: Hoon JC, Suk KY, Myung GC, editors. Clinical gastrointestinal endoscopy. SpringerVerlag Berlin Heidelberg, 2014.

3. Lombard MG, Morris AI, Morris AJ, Rösch T. Lower gastrointestinal tract. In: Atlas of Gastrointestinal Endoscopy and Related Pathology (2nd ed). UK: Blackwell Science, 2004; p. 227-8.

4. Lombard MG, Morris AI, Morris AJ, Rösch T. Endoscopic retrograde cholangiopancreatography. In: Atlas of Gastrointestinal Endoscopy and Related Pathology (2nd ed). UK: Blackwell Science, 2004; p. 343-4.

5. Departemen ilmu penyakit dalam FKUI. Pusat endoskopi saluran cerna (PESC). 2011 April [cited 2016 August 25]. Available from:

http://www.internafkui.or.id/index.php? page $=$ centerofexcellent.view $\&$ id $=2$

6. Kim BC, Lee JK, Choi HS, Seo JH, Lee SJ. Staging gastritis based on endoscopic atrophic border backed by operative link for gastritis assessment system in 158 health checkup subjects single center study. Korean J Helicobacter Up Gastrointest Res. 2014;14:109.

7. Putri CY, Arnelis, Asterina. Gambaran klinis dan endoskopi saluran cerna bagian atas pasien dyspepsia di bagian RSUP Dr. M. Djamil Padang. Jurnal Kesehatan Andalas. 2016;5:345-6 
8. Ariefiany D, Hassan AH, Dewaani BM, Yantisetiasti A. Analisis gambaran histopatologi gastritis kronik dengan dan tanpa bakteri helicobacter pylori menurut sistem Sydney. Majalah Patologi. 2014;23:23-4.

9. Teriaky A, Al Nasser A, McLean C, Gregor J, Yan B. The utility of endoscopic biopsies in patients with normal upper endoscopy. Canadian Journal of Gastroenterology and Hepatology. 2016;2016:3.

10. Makmun D. Pendekatan klinik nyeri perut. In: Rani AA, Maman C, Djojoningrat D, Kolopaking MS, Makmun D, Abdullah M, et al, editors. Dispepsia Sains \& Aplikasi Klinis (2nd ed). Jakarta: Divisi Gastroenterologi Departemen Ilmu Penyakit Dalam FKUI, 2005; p. 87-94.

11. Djojoningrat D. Dispepsia fungsional. In: Buku Ajar Ilmu Penyakit Dalam (5th ed). Jakarta: Balai Penerbit FK UI,
2009; p. 529-32.

12. Toulasik A, Maria R. Gambaran tingkat kecemasan pasien yang akan menjalani prosedur endoskopi saluran cerna di Rumah Sakit Pusat Angkatan Darat Gatot Soebroto Jakarta: FKUI, 2013; p. 3.

13. Hirlan. Gastritis. In: Sudoyo AW, Setiyohadi B, Alwi I, Simadibrata M, Setiati S, editors. Buku Ajar Ilmu Penyakit Dalam. Jakarta: Pusat Penerbitan Ilmu Penyakit Dalam FKUI, 2006.

14. Hirlan. Gastritis. In: Setiati S, Alwi I, Sudoyo AW, Simadibrata KM, Setiyohadi B, Syam AF, editors. Ilmu Penyakit Dalam (6th ed). Jakarta: Interna Publishing, 2014; p. 1768.

15. Lindseth GN. Gangguan lambung dan duodenum. In: Hartanto $\mathrm{H}$, Susi N, Wulansari P, Mahanani DA, editors. Patofisiologi Konsep Klinis Prosesproses Penyakit (6th ed). Jakarta: EGC, 2012; p. 423. 
Jurnal e-Clinic (eCl), Volume 4, Nomor 2, Juli-Desember 2016 